\title{
Microbial dominance and nutritional status in rhizosphric soil of Polyalthia longifolia over different monsoon seasons \\ Prateek Shilpkar ${ }^{1}$, Kinjal R. Modi ${ }^{1}$, Mayur C. Shah ${ }^{2}$ and Deepti Shilpkar ${ }^{3}$ \\ ${ }^{1}$ Biogas Res. \& Extension Centre; ${ }^{2}$ Dept. of Chemistry, Gujarat Vidyapith, Sadra, Gandhinagar Dt., Gujarat-382 320. \\ ${ }^{3}$ Department of Botany, Jai Narayan Vyas University, Jodhpur, Rajasthan, India
}

pshilpkar@yahoo.com

\begin{abstract}
A preliminary investigation was carried out on dominance of different types of microbial communities at different monsoon seasons in rhizospheric soils of Polyalthia longifolia trees. Nutrient contents of soil were also determined simultaneously to correlate with the microbial population. Results show that the dominance of microbial communities (actinomycetes, nitrogen fixers and yeasts) and soil nutrients content varied among premonsoon, monsoon and monsoon seasons. Actinomycetes were dominant during premonsoon season when lowest available nitrogen content was recorded in the rhizosphere milieu. Monsoon season favoured for the growth of diazotrophs in rhizosphere soil resulted in highest content of available soil nitrogen. This study may help in agricultural practices to manage the nitrogen fertilizers according to the season and also indicated the potential role of biofertilizers.
\end{abstract}

Keywords: Rhizospheric soil, microbial communities, nutrients content, Polyalthia longifolia.

Introduction

Ashoka (Polyalthia longifolia) plant, also known as Mast tree or Cemetery tree, is cultivated all over India. It is a tall, ornamental and evergreen tree. Its bark has medicinal properties to cure fever, skin diseases, diabetes, hypertension, helminthiasis and vitiated conditions of vata and pitta (Warrier et al., 2002). It is bitter, acrid, cooling, febrifuge and anthelmintic. Present study attempts to profile the microbial communities of its rhizospheric soil and its dynamics with reference to selected soil conditions.

Materials and methods

Rhizospheric soil from three $P$. longifolia trees grown independently, were collected aseptically in UV sterilized plastic bags in pre-monsoon (June, 2006), monsoon (September, 2006) and post-monsoon (November, 2006) seasons and analyzed for its various microbial and chemical parameters. It includes enumeration of viable organisms such as Rhizobium spp., Azotobacter spp., actinomycetes and yeast on specific media. The chemical parameters include $\mathrm{pH}$, electrical conductivity $(E C)$, organic carbon (OC), total and available nitrogen, available phosphorous, available potassium, calcium, magnesium and sodium.

\section{Microbial analysis}

Soil sampling $(10 \mathrm{~g})$ was done from three replicated sites and emulsified in $90 \mathrm{~mL}$ sterilized water, aseptically. A serial decimal dilution was made from this suspension up to $1: 10^{-10}$. One $\mathrm{mL}$ of each dilution was used to inoculate plates in triplicate containing specific growth media for different microorganism viz. congo-red yeast extract mannitol agar (for Rhizobium spp.), Ashby's mannitol agar (for Azotobacter spp.) Kenknight and Munaiers medium (for actinomycetes) and yeast extract agar (for yeast) (Subba Rao, 2001).

\section{Chemical analysis}

For chemical analysis, the soil samples were air dried and sieved to pass through a $2 \mathrm{~mm}$ sieve. The $\mathrm{pH}$ and electrical conductivity (EC) are determined using a 1:2.5 (w:v) soil: water ratio and Systronic $\mathrm{pH}$ meter and conductivity meter, respectively. Organic carbon is determined by wet oxidation method outlined by Walkley and Black (1934).

Available phosphorus and sodium are estimated using Olsen's method. $2.5 \mathrm{~g}$ soil is shaken with $50 \mathrm{~mL}$ of Olsen's reagent for 30 minutes on shaker followed by filtration through dry filter paper Whattman No: 1 . In the filtrate, phosphorus and sodium are estimated spectrophotometrically at $660 \mathrm{~nm}$. For total $\mathrm{N}$ estimation, $5 \mathrm{~g}$ soil is first digested by boiling with concentrated $\mathrm{H}_{2} \mathrm{SO}_{4}$ in the presence of copper catalysts and salts of $\mathrm{K}_{2} \mathrm{SO}_{4}{ }^{-}$till the solution becomes colorless. Ammonia contents of the digest are determined by distillation with excess $\mathrm{NaOH}$ and absorption of the evolved $\mathrm{NH}_{3}$ in standard $\mathrm{H}_{2} \mathrm{SO}_{4}$. Calcium and magnesium ions are retained in the adsorbed complex on soil. They are first replaced by percolating with neutral normal ammonium acetate solution followed by titration with $0.01 \mathrm{~N}$ EDTA (ethylene diamine tetra-acetic acid) solution using eriochrome black $T$ and murexide indicators respectively for determination of $\mathrm{Ca}+\mathrm{Mg}$ and $\mathrm{Ca}$ (Singh et al., 2001). Average values of microbial count and nutrients content for three replicates are presented in the result.

Results and discussion

Data in Table 1 reveals that microbial population present in all season in the dominance order of Azotobacter $>$ yeast $>$ Rhizobium > Actinomycetes. Highest count of Azotobacter is correlated with highest content of available nitrogen in the season (Table 2). This clearly reveals the enrichment of available nitrogen by diazotrophs.

Among various seasons, the better prevalence of actinomycetes population was noticed during premonsoon with lowest nitrogen content of the soil. The poor nitrogen content probably favoured the actinomycetes giving more survival edge but at the same time adverse to the competing microorganism to flourish.

In spite of considerable increase in number during pre-monsoon, the actinomycete population remained comparatively lesser in all seasons when compared to other microbial communities.
Research communication

(c)Indian Society for Education and Environment (iSee)
"Dynamics of rhizospheric microbial community" http://www.indjst.org
Prateek et al. Indian J.Sci.Technol. 
Increased amount of organic carbon, $\mathrm{C} / \mathrm{N}$ ratio and calcium was noticed during monsoon (Table 2). Probably the entry of rain water, enriched with dead animal and plant debris and minerals, into rhizospheric soil makes it nutritionally rich. The favorable moisture and nutritional conditions results in higher microbial growth and metabolic activity in monsoon compared to pre-monsoon season (Table 1). At this time, dominance of microbial communities is also changed and becomes as Azotobacter > Rhizobium >

yeast > Actinomycetes. Large effect of seasonal changes in soil moisture, soil temperature and carbon input on soil microbial biomass and its activity was also reported by Ross (1987) which in turn, affect the ability of soil to supply nutrients to plants through soil organic matter turnover (Bonde \& Roswall, 1987). Microbial biomass has been reported to vary seasonally in European soils (Patra et al., 1990). Singh et al. (1989) have also reported a seasonal variation in the microbial $\mathrm{C}, \mathrm{N}$ and $P$ in forest and savanna. Higher microbial growth utilizes phosphorous, potassium and magnesium and causes mineralization of nitrogen hence, amount of phosphorous, potassium and magnesium decreased and of available nitrogen increased during monsoon compared to premonsoon season (Table 2).

Count of all microbial communities studied decreased in post-monsoon compared to monsoon and pre-monsoon (Table 1). Here, dominance of microorganisms was yeast > Azotobacter > Rhizobium > Actinomycetes. Content of $\mathrm{C} / \mathrm{N}$ ratio, available nitrogen and calcium also decreased in postmonsoon compared to monsoon season (Table 2).

Research communication

CIndian Society for Education and Environment (iSee)
Table 1. Effect of seasons on microbial count $\left(X 10^{5}\right)$

\begin{tabular}{|l|l|l|l|}
\hline Microorganisms & \multicolumn{3}{|c|}{ Seasons } \\
\hline & $\begin{array}{c}\text { Pre- } \\
\text { monsoon }\end{array}$ & Monsoon & \multicolumn{1}{|c|}{$\begin{array}{l}\text { Post- } \\
\text { monsoon }\end{array}$} \\
\hline Rhizobium & 33.85 & $\begin{array}{l}891.09 \\
2532.47^{*}\end{array}$ & $\begin{array}{l}4.18 \\
(-) 87.65^{* *} \\
(-) 99.53^{* * *}\end{array}$ \\
\hline Azotobacter & 616.98 & $\begin{array}{l}1519.89 \\
146.343^{*}\end{array}$ & $\begin{array}{l}9.15 \\
(-) 98.52^{* *} \\
(-) 99.40^{* * *}\end{array}$ \\
\hline Actinomycetes & 0.062 & $\begin{array}{l}0.0207 \\
(-) 66.61^{*}\end{array}$ & $\begin{array}{l}0.0099 \\
(-) 84.03^{* *} \\
(-) 52.17^{* * *}\end{array}$ \\
\hline Yeast & & $\begin{array}{l}32.97 \\
(-) 93.04^{* *} \\
(-) 95.33^{* * *}\end{array}$ \\
\hline
\end{tabular}

$\%$ increase in microbial count during *monsoon over pre-monsoon season; ${ }^{* *}$ post-monsoon over pre-monsoon season; ${ }^{* * *}$ post-monsoon over monsoon season

Table 2. Effect of season on soil nutrient content

\begin{tabular}{|c|c|c|c|c|}
\hline Nutrients & & Seasons & & grassland soil which have \\
\hline & $\begin{array}{c}\text { Pre- } \\
\text { monsoon }\end{array}$ & Monsoon & $\begin{array}{l}\text { Post- } \\
\text { monsoon }\end{array}$ & $\begin{array}{lr}\text { been under } & \text { uniform } \\
\text { management for many }\end{array}$ \\
\hline $\begin{array}{l}\mathrm{pH}(1: 2.5 \\
\text { soil: water } \\
\text { ratio) }\end{array}$ & 7.67 & $\begin{array}{l}8.32 \\
8.47^{*}\end{array}$ & $\begin{array}{l}8.52 \\
11.08^{* *} \\
240^{* * *}\end{array}$ & $\begin{array}{l}\text { years. Soil Biol. Bic } \\
249-253 \text {. }\end{array}$ \\
\hline
\end{tabular}


\begin{tabular}{|l|l|l|l|l|l} 
EC & 0.27 & 0.26 & 0.36 & 3. & microbial biomass estimated \\
\hline
\end{tabular}



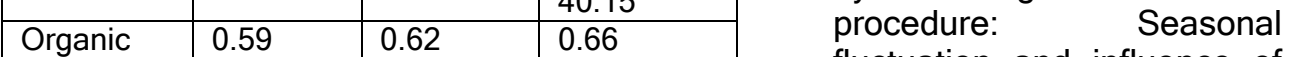
\begin{tabular}{l|l|l|l|l}
\hline Organic & 0.59 & 0.62 & 0.66 & fluctuation and influence of \\
Carbon & & $5.03^{*}$ & $10.37^{* *}$ & $5.08^{*}$
\end{tabular} \begin{tabular}{|l|l|l|l}
$(\%)$ & & $5.08^{* * *}$ & soil moisture content. Soil
\end{tabular} \begin{tabular}{|l|l|l|l|l} 
& & & Biol. Biochem. 19, 397-404.
\end{tabular}

\begin{tabular}{|l|l|l|l} 
Nitrogen & 1.23 & $\begin{array}{l}0.47 \\
(-) 61.79^{*}\end{array}$ & $\begin{array}{l}0.84 \\
(-) 31.71^{* *}\end{array}$
\end{tabular} \begin{tabular}{|l|l|l|l}
$(\%)$ & $78.72^{* * *}$ & Pandey RN (2001) Soil, plant
\end{tabular} \begin{tabular}{|l|l|l|l|l} 
C:N Ratio & 0.48 & 1.31 & 0.88 & and water analysis: methods
\end{tabular} \begin{tabular}{l|l|l|l}
$172.71^{*}$ & $82.53^{* *}$ & manual. Div. of Soil Sci. \&
\end{tabular}

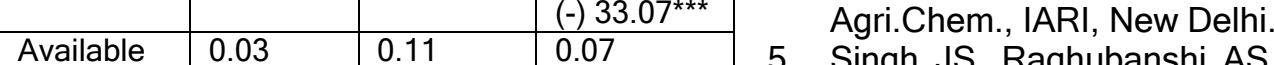
\begin{tabular}{|l|l|l|l|l}
\hline Available & 0.03 & 0.11 & 0.07 & 5. Singh JS, Raghubanshi AS, \\
Nitrogen & & $266.67^{*}$ & $133.33^{* *}$ & S.
\end{tabular} \begin{tabular}{|l|l|l|l}
\hline$\%$ & $266.67^{*}$ & $(-) 36.36^{* * *}$ & Singh RS and Srivastava SC
\end{tabular}

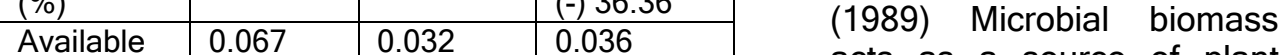
\begin{tabular}{l|l|l|l|l} 
Available & 0.067 & 0.032 & 0.036 & acts as a source of plant \\
Phosphoru & & $(-) 52.24^{*}$ & $(-) 46.27^{* *}$ & (-) $4.5 * 2$
\end{tabular} \begin{tabular}{|l|l|l|l}
$\mathrm{s}(\%)$ & $(-) 52.24^{*}$ & $(-) 46.27^{* *}$ & $12.5^{\star * *}$
\end{tabular}$\quad$ nutrients in dry tropical forest

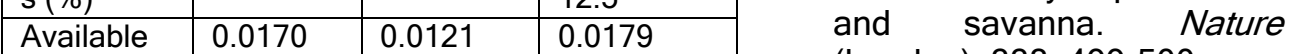
\begin{tabular}{l|l|l|l} 
Potassium & $(-) 28.82^{*}$ & $5.29^{* *}$ & (London). 338, 499-500.
\end{tabular}

\begin{tabular}{l|l|l|l}
$(\%)$ & & $47.93^{* * *}$ & 6. Subba Rao NS (2001) Soil
\end{tabular}

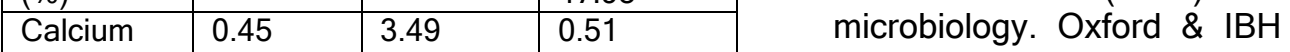

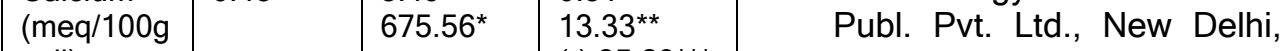
\begin{tabular}{|l|l|l|l} 
soil) & & $(-) 85.29^{* * *}$ & India.
\end{tabular}

\begin{tabular}{|c|c|c|c|}
\hline $\begin{array}{l}\text { Magnesiu } \\
\mathrm{m} \\
\text { (meq/100g } \\
\text { soil) }\end{array}$ & 3.46 & $\begin{array}{l}0.41 \\
(-) 88.15^{*}\end{array}$ & $\begin{array}{l}0.56 \\
(-) 83.82^{* *} \\
36.59^{* * *}\end{array}$ \\
\hline $\begin{array}{l}\text { Sodium } \\
\text { (\%) }\end{array}$ & 0.07 & $\begin{array}{l}0.02 \\
(-) 66.31^{*}\end{array}$ & $\begin{array}{l}0.80 \\
1136.31^{* *} \\
3569.41^{* * *}\end{array}$ \\
\hline
\end{tabular}

$\%$ increase in nutrients content during *monsoon over pre-monsoon season; ** post-monsoon over pre-monsoon season; ${ }^{* * *}$ post-monsoon over monsoon season

"Dynamics of rhizospheric microbial community" http://www.indjst.org
7. Walkley AJ and Black IA (1934) Estimation of soil organic carbon by chromic acid titration method. Soil Sci. 37, 29-38.

8. Warrier PK, Nambiar VPK and Ramankutty C (2002) Indian medicinal plants. IV. Orient Blackswan, India. pp: 330. Indian J.Sci.Technol. 